\title{
Availability of COVID-19 Information from National and International Hand Surgery Society Websites
}

\author{
Sammy Al-Benna ${ }^{1, \odot}$ Andreas Gohritz ${ }^{2, \odot}$ \\ ${ }^{1}$ Division of Plastic and Reconstructive Surgery, Faculty of Medicine \\ and Health Sciences, Stellenbosch University and Tygerberg \\ Academic Hospital, Cape Town, South Africa \\ 2Department of Plastic, Reconstructive, Aesthetic and Hand \\ Surgery, University Hospital Basel, Basel, Switzerland
}

\author{
Address for correspondence Sammy Al-Benna, MBChB, PhD, \\ FAPÄC, Division of Plastic and Reconstructive Surgery, Faculty \\ of Medicine and Health Sciences, Stellenbosch University and \\ Tygerberg Academic Hospital, Francie van Zijl Drive, PO Box 241, \\ Cape Town, 8000, South Africa \\ (e-mail: albenna@sun.ac.za).
}

J Hand Microsurg 2021;13:257-258.

The novel coronavirus disease 2019 (COVID-19) pandemic is an unprecedented global crisis that impacts us all and still persists. ${ }^{1}$ Health care systems worldwide focus on providing effective patient care and hospital capacity and minimize transmission risks by personal protective equipment (PPE), considering the availability of finite and essential resources and supply chains supporting health services. Hand surgeons are forced to reconsider almost every facet of their clinical practice to maintain emergency and essential hand surgery. ${ }^{2-4}$ National and international surgery societies are seen as reliable sources of information for clinical information and guidelines. ${ }^{5}$ However, no studies have assessed the information available on national and international hand surgery societies' web sites.

An assessment of information available on hand surgery society web sites with regard to COVID-19 information in all United Nations sovereign states was performed. ${ }^{6}$ A Google search was performed to that used the terms "hand" and "surgery" and "society OR association" and "(Name of nation of interest)." Each web site was assessed for COVID-19 information, clinical practice guidelines, and links. All national societies associated with the International Federation of Societies for Surgery of the Hand (IFSSH), the Federation of European Societies for Surgery of the Hand, Asian Pacific Federation of Societies for Surgery of the Hand, and South American Federation for Surgery of the Hand were included and COVID-19 information was recorded. ${ }^{7-9}$ This was performed on March 31, 2020.

Out of 193 United Nations member sovereign states, 61 (32\%) had a national hand surgery society. Only 43 (22\%) of those had a national hand surgery society web site. COVID-19 was mentioned in only $19 \%$ of those national hand surgery society web sites, of which $12 \%$ of societies advised to provide only urgent or emergent care. Only $7 \%$ of societies provided their own
COVID-19 advice. $12 \%$ provided their state's directives to provide only urgent or emergent care; none recommended following World Health Organization (WHO) guidelines. COVID-19 was mentioned in 8 of $43(19 \%)$ of those national hand surgery society web sites of which 5 of 43 (12\%) societies advised to provide only urgent or emergent care. Only 3 of 43 (7\%) societies provided their own COVID-19 advice. Five of 43 (12\%) provided their state's directives to provide only urgent or emergent care; none recommended following WHO guidelines. All four international hand surgery societies had a web site, one was inaccessible. COVID-19 was not mentioned in the three accessible international hand surgery society web sites.

COVID-19 information was scarce on national and international hand surgery web sites with over two-thirds of sovereign nations not represented. There were no links between national hand surgery web sites other than to conferences and courses. COVID-19 information, clinical guidelines, and patient information sheets were in general rather rare on those web sites. Few national hand societies provided significant resources including COVID-19 recommendations for management of urgent and elective hand surgery procedures, carefully analyzed national and international recommendations and guidelines, and gave both general and specific advice with regularly updated resources.

COVID-19 has prompted a cascade of reports, an indistinct amalgam of unsubstantiated information, helpful information, misinformation and disinformation. Hand surgery society web sites could provide open access to peer-reviewed articles on COVID-19 from leading medical journals to support their members on the front lines, but also high-quality, evidence-based information enabling information technology platforms optimizing hand surgery education and standards of care. ${ }^{10-13}$, Clinical practice guidelines may improve quality of published online

October 29, 2020 (c) 2020. Society of Indian Hand \&

Microsurgeons. All rights reserved. Thieme Medical and Scientific Publishers Pvt. Ltd., A-12, 2nd Floor, Sector 2, Noida-201301 UP, India
DOI https://doi.org/ 10.1055/s-0040-1718864 ISSN 0974-3227. 
care and help in summarizing evidence, standardizing training, patient management, and guiding appropriate referrals.

Social media groups provide social support and allow shared global peer experiences and education, and could improve the interaction between national and international hand surgery societies and hand surgeons. It is important to acknowledge that confidentiality is an issue when discussing surgery in social media. It is necessary to promote the use of links between national and international surgical societies when seeking information on COVID-19. In an increasingly technological health system, where the internet and communication play a crucial role, it is essential that this deficiency should be addressed. ${ }^{10-12}$

This study is limited by the nature of internet, namely, that information changes continuously; like others, this study analyzed the information available at a particular time. ${ }^{10-12}$ Another limitation is that it could not evaluate if direct information was provided by the national or international hand society directly to their members, for example, by e-mail. ${ }^{10-12}$

It is suggested that improvement and increase in COVID-19 information provided by many national and international hand surgery society web sites is needed. ${ }^{10-12}$ The most up to date, thorough, and correct expert information will assist hand surgeons in making decisions regarding the COVID-19 pandemic and care for hand surgery patients. ${ }^{10-14}$

\section{Conflict of Interest}

None declared.

\section{References}

1 Al-Benna S. Impact of COVID-19 on Surgical Registrars' Education and Training. S Afr J Surg 2020;58:10-13

2 Al-Benna S. Management of hand surgery services during the novel coronavirus disease 2019 pandemic. J Hand Microsurg 2020. Doi: 10.1055/s-0040-1714440
3 Ducournau F, Arianni M, Awwad S, et al. COVID-19: Initial experience of an international group of hand surgeons. Hand Surg Rehabil 2020;39(3):159-166

4 Hwee J, Chiew J, Sechachalam S. The impact of coronavirus disease 2019 (COVID-19) on the practice of hand surgery in Singapore. J Hand Surg Am 2020;45(6):536-541

5 Al-Ajam Y, Al-Benna S. Burns associations and societies websites-Do they provide enough information for patients and doctors? Burns 2009;35:S42

6 United Nations. Member states. Available at: https://www. un.org/en/member-states/. Accessed March 31, 2020

7 International Federation of Societies for Surgery of the Hand. Allied Organisations. Available at: https://www.ifssh.info/ allied_organisations.php\#. Accessed March 31, 2020

8 Federation of European Societies for Surgery of the Hand. National Delegates. Available at: http://fessh.com/national-delegates/. Accessed March 31, 2020

9 Asian Pacific Federation of Societies for Surgery of the Hand. Member Societies. Available at: http://www.apfssh. net/?act=info.page\&pcode=sub1_5. Accessed March 31, 2020

10 Al-Benna S. Availability of COVID-19 Information from National and International Aesthetic Surgery Society websites. Aesthetic Plast Surg 2020;44(3):1043-1046

11 Al-Benna S, Gohritz A. Availability of COVID-19 information from national plastic surgery society websites. Ann Plast Surg 2020;85(2S, suppl 2):S171-S172

12 Al-Benna S, Gohritz A. Availability of COVID-19 information from national and international burn society websites. Ann Burns Fire Disasters 2020;33(3)177-181

13 Al-Benna S. Concepts of management of plastic surgery services during the coronavirus disease 2019 pandemic. Eur J Plast Surg 2020. Doi: 10.1007/s00238-020-01704-1

14 Al-Benna S. Construction and use of wound care guidelines: an overview. Ostomy Wound Manage 2012;58(8):37-47 